\title{
Corrosion protection of steel reinforcement by using surface applied corrosion inhibitors
}

\author{
Engin Cueneyt Seyhan ${ }^{1, *}$ Fred Goodwin ${ }^{2}$, and I-Wen (Evan) Huang ${ }^{2}$ \\ ${ }^{1}$ BASF Construction Chemicals, Regional Business Segment Management Europe, Piccardstr. 11, 86159 Augsburg, Germany \\ ${ }^{2}$ BASF Construction Chemicals, Global Corrosion Competency Center, 23700 Chagrin Blvd, 44122 Beachwood, USA
}

\begin{abstract}
Surface applied corrosion inhibitors (SACI) are widely used to mitigate the corrosion process of steel reinforcement in concrete. But they remain controversial as to their effectiveness and the ability to compare materials from different manufacturers and technologies. They are applied onto the surface of hardened concrete and penetrate towards the steel reinforcement. This paper discusses the corrosion inhibition performances of a dual-phase corrosion inhibitor and field surveys through corrosion monitoring the selected structures. The efficiency of the corrosion inhibitor is assessed by selected testing procedures in laboratories.
\end{abstract}

\section{Concrete deterioration and cost of corrosion}

Concrete is the most widely used construction material in the last two centuries. Local availability of ingredients such as sand and cement, ease of shaping and high compressive strength made concrete the best alternative to masonry for the building of new structures. As this man-made stone could not provide adequate tensile strength, engineers had to incorporate steel to overcome this deficiency. The advent of reinforced concrete led to innovative uses of concrete for all types of structures and made reinforced concrete the material of choice for designers and builders. However, it is a disturbing truth that corrosion of the steel represents a major problem for the longevity of the structures concerned. Although the cement matrix provides physical protection and the highly alkaline environment keeps steel reinforcement in a passive state, it has been observed that corrosion of the reinforcing steel has initiated in almost every structure sooner or later.

Over the past 50 years, corrosion has emerged as the most significant cause of damage to reinforced concrete structures. Apart from the considerable expense of refurbishment work, the loss of access or use also results in significant cost. Considering the five major sectors of infrastructure: utilities, transportation, manufacturing industry and government, the total annual cost of corrosion-related repairs throughout the world is estimated at US\$2.5 trillion, corresponding to about 3.4\% of the world's Gross Domestic Product (GDP) (2013) [1]. Corrosion repairs to reinforced concrete structures such as roads, bridges, marine structures, industrial buildings, commercial and residential buildings account for a significant share of the total direct cost of corrosion. The indirect cost to the community of corrosion damage is hard to estimate but, based on a life cycle analysis of corrosion maintenance, repair, and rehabilitation for bridges in the USA, the cost in terms of lost productivity, traffic delays etc. could be as high as the direct costs [2].

\section{Corrosion of steel reinforcement}

Corrosion may be defined as the conversion of a refined metal (in this case steel) into its more stable oxides, with the consumption of oxygen and water. These electrochemical reactions take place at two distinct locations on a metal component, the anode (1) and the cathode (2) [3].

$$
\begin{gathered}
\mathrm{Fe} \rightarrow \mathrm{Fe}^{+2}+2 e^{-} \\
2 e^{-}+\mathrm{H}_{2} \mathrm{O}+1 / 2 \mathrm{O}_{2} \rightarrow 2 \mathrm{OH}^{-}
\end{gathered}
$$

Concrete provides a natural shield, protecting the steel reinforcement against corrosion. The highly alkaline environment created by the cement matrix surrounding the reinforcement bars results in the formation of a passive layer around the steel. This passive film is only a few nanometers thick and is composed of hydrated iron oxides with a varying degree of $\mathrm{Fe}^{2+}$ and $\mathrm{Fe}^{3+}$ [4]. This passive layer is an impermeable oxide film which prevents further corrosion reactions by keeping oxygen and water away from the metal surface. This protective film is maintained if the highly alkaline environment provided by the concrete matrix persists. However, this passive condition cannot be maintained over the course of time because of deterioration occurring within the concrete. In chloride attack, chloride ions are transported through the concrete to the steel. This disrupts the passive layer and leads to corrosion. In addition, carbonation due to exposure to carbon dioxide dissolved in water reduces the $\mathrm{pH}$ of the cement matrix, which also resulting with breakdown of the passive layer and furthermore increases

* Corresponding author: engin.seyhan@basf.com

(C) The Authors, published by EDP Sciences. This is an open access article distributed under the terms of the Creative Commons Attribution License 4.0 
the free chlorides by releasing the bound ones. Once the passive layer breaks down, corrosion reactions start, rapidly attacking the reinforcement bars. Water and oxygen are the only ingredients which are needed for the reactions to continue. Depending on the corrosion rate, the reinforcement bars push off the concrete cover due to volume expansion of the corrosion product and eventually lose their bond to the concrete, which compromises the structural integrity.

\section{Corrosion protection of steel reinforcement}

Corrosion of steel in concrete is an electrochemical process. A corrosion cell requires both an anodic site, where the metal is dissolved, and a cathodic site, where oxygen is reduced, and hydroxyl ions are produced; it also requires electronic conduction paths (through the reinforcing steel) and ionic or electrolytic conduction paths (through the pore-electrolyte). To reduce the rate of corrosion, a reduction in the rate or elimination of the associated processes is required [5].

\subsection{Use of silanes in concrete protection}

Chloride ions diffuse into concrete along with the water and deteriorate the protective passive layer around the steel reinforcement and initiate or accelerate the corrosion process. Water is the main chemical compound along with oxygen, which are both consumed in corrosion reactions. Therefore, restricting water ingress and keeping chloride ions out of the concrete matrix reduces the corrosion rates significantly.

Silanes are a diverse class of chemicals of organosilicon molecules of various functions and sizes. The small size of silane molecules means that they can penetrate deep into the concrete, where they can form chemical bonds with the hydrated components of the cement matrix due to their silica structure. After reacting with concrete, silane molecules repel the water and stop further chloride ions from penetrating the concrete $[6,7,8]$. Any water already present in the concrete can evaporate through open pores since this water-repellent layer created by silanes is considered 'breathable'.

Alkyltrialkoxysilanes are composed of an alkyl group that serves as a water repellent and three alkoxy groups for chemical reactivity and bonding, all joined to a silicon atom. The effectiveness of silanes depends on the type of alkyl group in size and branching, the molecular weight, and the reaction rate and surface tension of the silane liquid [9]. It is critical to select the suitable alkyl chains for formulating the silane blends for achieving the best performance on concrete substrates. Besides the water repellency, the resistance to carbonation by water repellency is the key for long term performance.

\subsection{Corrosion inhibitors}

NACE International defines corrosion inhibitor as "a chemical substance that, when added in small concentration to an environment, effectively decreases the corrosion rate". Based on the electrochemical mechanism of action alone, all inhibitors fit into one of three broad classes: (a) anodic, (b) cathodic and (c) mixed, depending on whether they affect the anodic reaction, the cathodic reaction, or both [10]. These inhibitors are chemical compounds, which can be carried to the steel reinforcement in different ways. They can be added to concrete admixtures and mixed directly with the fresh concrete. Unfortunately, this method is limited to fresh concrete and only relevant for new structures. In the European construction industry, the refurbishment of existing structures accounts for a large part of activities. In view of this fact, scientists have developed various types of surface-applied corrosion inhibitors (SACI) to stop existing corrosion processes in hardened concrete.

Silanes are used as an effective corrosion inhibitor due to their excellent hydrophobicity on concrete surfaces. Besides silanes, amines (e.g. aminoalchohol, aminocarboxylates) and sodium monofluorophosphate (MFP) are known SACIs for protecting steel reinforcement. However, the efficiency of these inhibitors on reinforced concrete are limited under certain conditions. For instance, MFP shows very little effectiveness on the corrosion rates of steel in both noncarbonated and carbonated concretes [11]. Several experimental studies and field surveys revealed that the amine-based inhibitors (aminoalcohol and aminocarboxylates) also have very limited impact on inhibiting corrosion $[12,13,14,15]$.

\section{Dual phase corrosion inhibitor}

In the light of research carried out over the past two decades, BASF scientists succeeded in combining silanes and selected corrosion inhibitors to develop a new type of surface-applied corrosion inhibitor. This product is a clear liquid with combination of high-quality blended silanes and selective corrosion inhibitors (including latent phase inhibitors) and is designed to break the corrosion mechanism in reinforced concrete structures in various conditions. Silane technology allows deep penetration into the concrete and chemical bonding, which avoids wash out. In addition, the high alkali resistant nature of silanes leads to long service life when used on concrete surfaces. While the silane backbones of the product guarantee high water repellency and the exclusion of water and chloride ions, selective corrosion inhibitors stop the corrosion reactions and help the reinforcement bar to restore its passive layer. The presence of latent phase inhibitor lies dormant within the concrete until activated by moisture, which then penetrates the surface through cracks in concrete and sustains effective corrosion protection even after the silane barrier breaks down. This spectacular performance leads to a significant extension of service life and the maintenance-free period and reduces refurbishment costs.

\subsection{Working mechanism}

Dual phase corrosion inhibitor employs dual functionality. The silane base (alkylalkoxysilane) 
provides similar benefits to the water-repellent sealers, and the integral corrosion inhibitors are carried into the concrete along with the silane. The latent phase inhibitors remain inactive in the concrete until the water repellency diminishes over time, or until the concrete cracks. They then become mobile and are carried deeper into the concrete by moisture. Dual phase inhibitor has a surface tension roughly $1 / 3$ that of water, and low viscosity to improve penetration into concrete. Its special blend of silanes provides a balance between drying time and penetration over a wide temperature range, as well as lower VOC content and a higher flash point than many traditional silane-based inhibitors. The result is a very fluid material with viscosity close to water, which can be applied via spray, brush or roller.

The most observable property of dual phase inhibitor is water repellency on the concrete surface. The silane component of dual phase inhibitor provides the same benefit with the added feature of its ability to act as a corrosion inhibitor. The alkylalkoxysilane structure of the dual phase inhibitor protects concrete from penetration of liquid water, but it keeps concrete permeable to water vapor. Thus, while keeping additional water from penetrating into the concrete, it will allow any moisture contained in the concrete to evaporate. Dual phase inhibitor utilizes multiple silane functionalities to create different effects on the concrete substrate. These include the formation of a hydrophobic shield as well as a corrosion inhibition effect.

Creation of the hydrophobic properties begin when the silane hydrolyzes to form silanol and alcohol. Next the silanol group condenses, forming a bond to hydroxides on the concrete surface. Fig. $1[16,17]$ depicts the chemical reactions associated with this process.
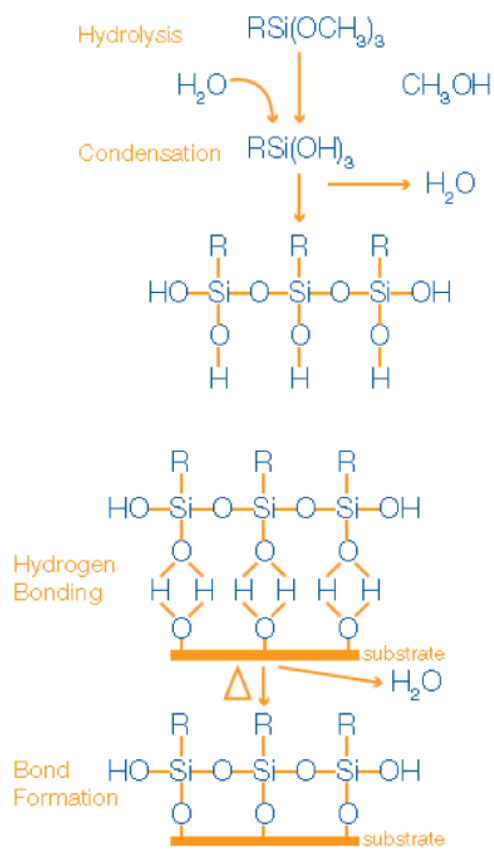

Fig. 1. Reaction of alkyl alkoxy silane with water (hydrolysis) to produce silanol and alcohol followed by condensation and bonding to the pores of the concrete substrate.
The $\mathrm{R}$ in the figure represents the hydrophobic portion of the chemical compound. $\mathrm{CH}_{3} \mathrm{OH}$ is the methanol produced when dual phase inhibitor reacts with water. The substrate in this case is the pores in the concrete. This series of reactions leads to the formation of the hydrophobic layer (in molecular level) observed on and in the surface of the concrete treated with dual phase inhibitor.

Alkylalkoxysilanes can react within the concrete to reduce the conductivity of the electrolyte. The reaction increases the resistivity of the concrete immediately adjacent to the reinforcing steel which in turn slows down the electrochemical reactions for the corrosion process.

\subsection{Experimental studies}

Independent testing of dual phase corrosion inhibitor has shown it to be very effective at reducing active corrosion in steel reinforced concrete. The combination of the silane blend and the latent corrosion inhibitors serves synergistically to reduce active corrosion and prevent the onset of additional corrosion activity.

\subsubsection{ICCET testing laboratories}

An experimental study to determine the corrosion protection of reinforced concrete structures from chloride ion attack and carbonation by surface applied dual phase corrosion inhibitor was done in Eduardo Torroja Institute (ICCET) laboratories in Spain. The study was conducted on standard mortar (acc. EN 196-1) specimens with embedded steel reinforcement. The specimens were exposed to induce corrosion either by admixed chloride ions or a $100 \% \mathrm{CO}_{2}$ atmosphere, after which their surface was treated with the inhibitor. Steel corrosion was monitored via electrochemical tests to determine corrosion potential, corrosion rate, and electrical resistance of the hardened mortar specimens.

The first phase of the experimental study was determining the efficiency of the inhibitor in case of chloride induced corrosion. This test was designed to determine the efficiency of the corrosion inhibitor with admixed chloride ions. This entailed adding $2 \mathrm{wt} \%$ (cement) $\mathrm{Cl}$ - in the form of $\mathrm{CaCl}_{2}$ to the mixing water. Corrosion rate, corrosion potential, and resistivity measurements were taken 24-hours after mixing until the measurements verified the onset of corrosion. The inhibitor was then applied onto the specimens.

The corrosion rates observed for the specimens prepared with admixed chlorides are shown in Fig. 2. The blue lines represent the steel in the untreated reference specimen and the green and orange lines represent the specimens treated with the inhibitor. 


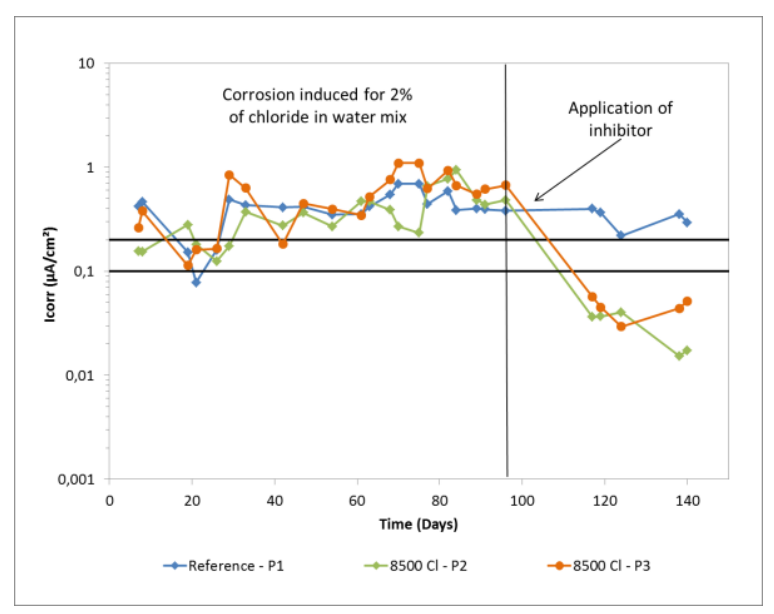

Fig. 2. Mean steel corrosion rate for specimens bearing chloride ions in the mixing water.

The data for the first period depicted in Fig. 2 (corrosion induced by $2 \%$ admixed chloride by weight of cement), i.e., the corrosion rates prior to applying the inhibitor, confirmed these three specimens are pre-corroded. At day 95, random specimens with active corrosion were selected and treated with the inhibitor. It was then noticed that the corrosion rate declined drastically below $0.1 \mu \mathrm{A} / \mathrm{cm}^{2}$ (steel de-passivation threshold) and remained below that value until the end of the tests. On the other hand, the control specimen (blue line) continued to exhibit mean corrosion values of $0.4 \mu \mathrm{A} / \mathrm{cm}^{2}$.

In addition to corrosion currents, electrical resistance of the specimens was also investigated. The concrete electrical resistance curves before and after surface treatment in Fig. 3 shows that electrical resistance rose steeply 24 hours after application.

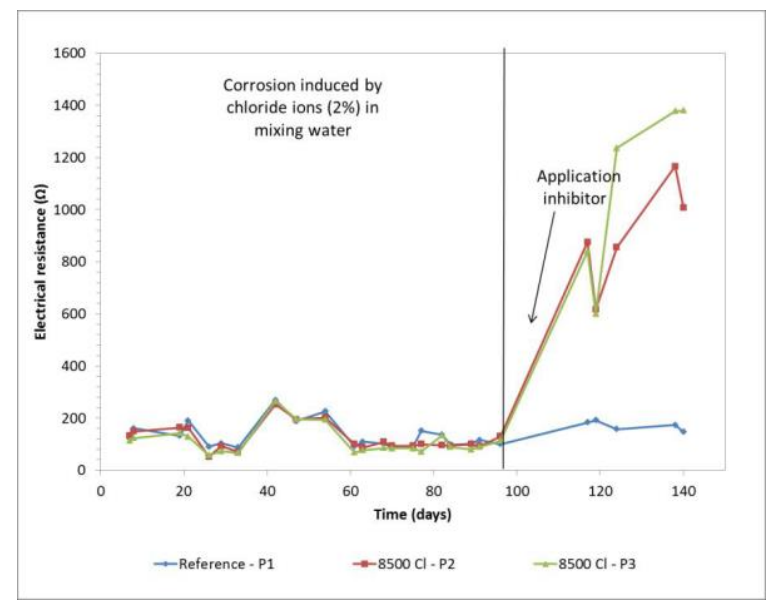

Fig. 3. Mean electrical resistivity rate for specimens bearing chloride ions in the mixing water.

The second phase of the experimental study was determining the efficiency of dual phase inhibitor in case of carbonation induced corrosion. The corrosion rate for the specimens exposed to accelerated carbonation in a 100 $\% \mathrm{CO}_{2}$ atmosphere is plotted in Fig. 4.

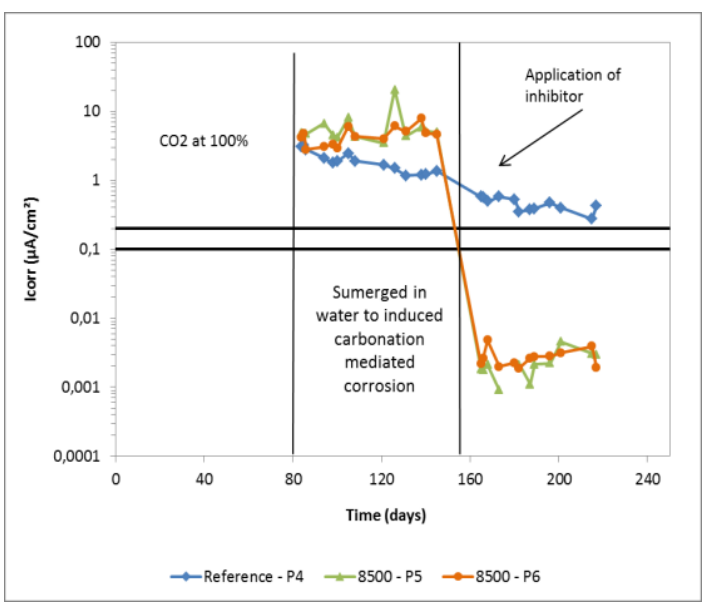

Fig. 4. Mean steel corrosion rate for specimens exposed to accelerated carbonation.

After 80 days of exposure and immersion in water, the steel embedded in the specimens exhibited high corrosion rates $\left(5 \mu \mathrm{A} / \mathrm{cm}^{2}\right)$. Once the product was applied, however, the values declined to under $0.1 \mu \mathrm{A} / \mathrm{cm}^{2}$ steel depassivation threshold. These values continued another 60 days until the end of the test.

Fig. 5 shows electrical resistance of concrete before and after corrosion treatment. Here initial electrical resistance was very high due to prior specimen exposure to accelerated carbonation, which raised this parameter substantially. After treatment, resistance rose even further, to over $10.000 \wedge$.

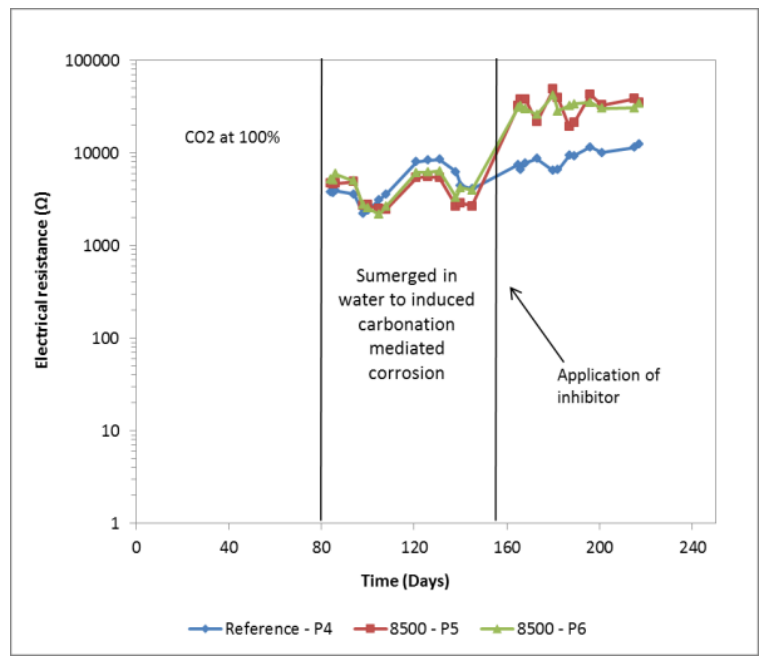

Fig. 5. Mean electrical resistivity for specimens exposed to accelerated carbonation.

\subsubsection{ASTM G 109}

ASTM G109 is a test method for "determining the effects of chemical admixtures on the corrosion of metals in concrete" [18]. The specimens, which were built according to this test standard were modified for corrosion inhibitor testing, shown in Fig. 6. 


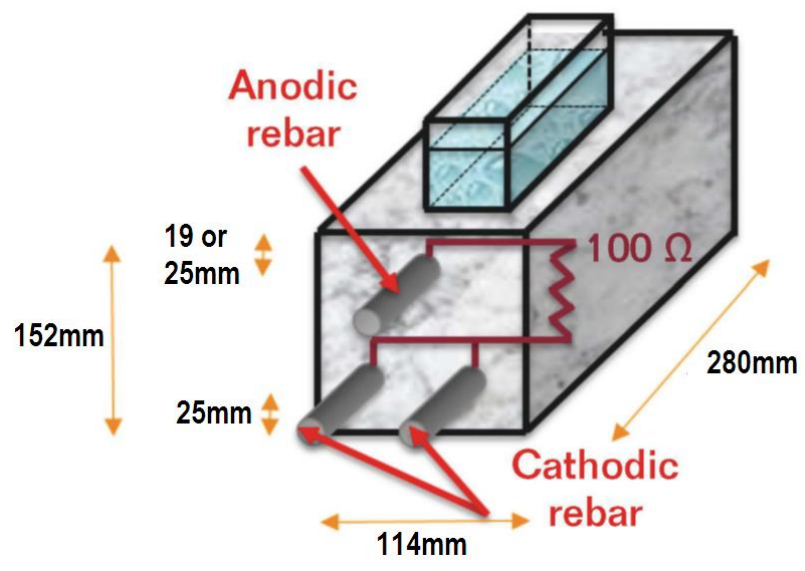

Fig. 6. ASTM G109 specimens modified for SACI testing.

The configuration for ASTM G109 is used, but instead of the test material being admixed into the concrete, the dual phase corrosion inhibitor is applied to the top surface of the hardened concrete specimen and allowed to dry before installing the ponding dam and coating the sides of the specimen with epoxy.

Before applying the inhibitors, the sample surface was abrasive blasted to ICRI CSP 5-6 after curing. Then they were treated with different silane-based surface applied corrosion inhibitors including dual phase corrosion inhibitor and an amino-functional silane and ponded with $3 \%$ sodium chloride $(\mathrm{NaCl})$ solution one week after the SACI treatment. In this testing, both corrosion inhibitors worked well, as shown by the total coulombs of corrosion current between the upper and lower bars, Fig. 7.

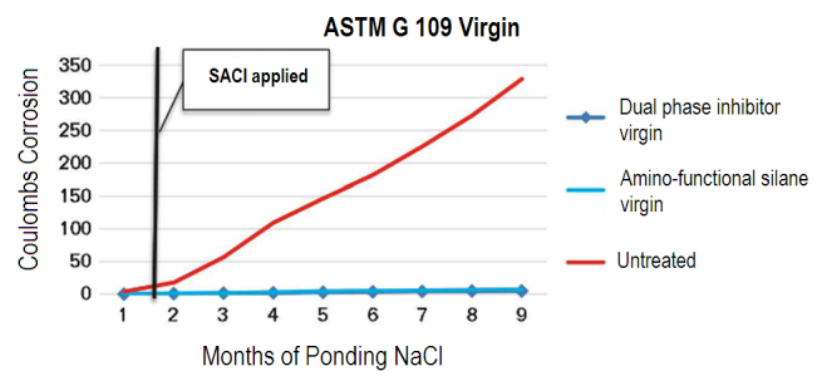

Fig. 7. ASTM G109 specimens treated with dual phase inhibitor, amino-functional silane, and an untreated control specimen.

As is easily seen in Fig.7, there is no appreciable difference between the two treated specimens after nine months of ponding. Both inhibitors reduced the corrosion rate drastically. In order to test the dual functionality and the efficiency of the latent phase inhibitors, another series of tests have been done by using modified ASTM G 109 specimens. Three specimens were cracked before the treatment with the corrosion inhibitor, and an additional three specimens were cracked after treated with the dual phase inhibitor. The crack widths were approximately $0.3 \mathrm{~mm}$ for both pre (before treatment) and post-cracked (after treatment) samples. Specimens were ponded with
$3 \% \mathrm{NaCl}$ for two weeks followed by drying at $50 \%$ relative humidity to simulate the accelerated corrosion conditions. During ponding with chlorides, corrosion current was measured between the upper and the lower bars. The accumulated corrosion current demonstrated that latent phase inhibitors in the new material reduces the corrosion rates significantly, represented in Fig. 8. This proves the dual functionality of the new material enhanced with latent phase inhibitors.

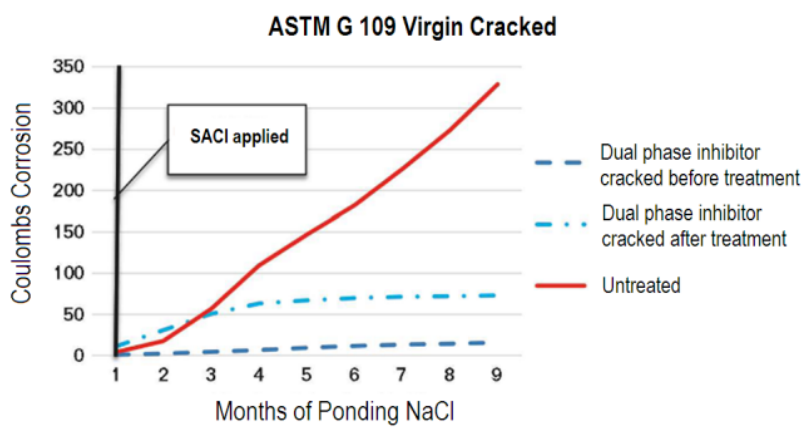

Fig. 8. ASTM G109 specimens treated with dual phase corrosion inhibitor before and after cracking, and an untreated control specimen.

\section{Summary and outlook}

Corrosion of reinforcing steel is the leading cause of deterioration of concrete structures around the world. Guidance exists for design and construction practices to produce durable structures; however, corrosion-induced deterioration continues due to failure to follow good trade practices. Concrete requires maintenance, especially to correct issues from cracking. Use of SACIs is a maintenance technique that can be applied proactively to existing structures as well as reactively to mitigate corrosion. Silane-based materials reduce chloride ingress and allow concrete drying to increase resistivity, both reducing corrosion. Incorporating latent corrosion inhibitors into silane-based surface treatments combines the benefits resulting from silane treatments and the corrosion inhibiting effects in concrete with cracks before, or even after treatment.

Experimental studies have revealed the significant high performance of dual phase inhibitor when compared to traditional corrosion inhibitors. ASTM G109 tests show that it performs well in both uncracked and cracked samples. In addition, the efficiency of the latent phase inhibitor is proved on the post-cracked specimens. In addition to superior performance obtained in the ASTM G109 test program, the inhibitor efficiency has been also proved in the experimental studies performed in Torroja Institute. Dual phase inhibitor not only performed outstandingly in the specimens subjected to a high amount of chloride ions, but also in the carbonated specimens. This guarantees that reinforced concrete elements can be protected effectively against both chloride and carbonation induced corrosion. 


\section{References}

1. G. Koch, J. Varney, N. Thompson, O. Moghissi, M. Gould, J. Payer: International measures of prevention, Application, and Economics of Corrosion Technologies Study, NACE International Report, Houston, (2016)

2. FHWA-RD-01-159 Report, Corrosion Costs and Preventive Strategies in the United States, (2001)

3. BRE Digest 444 Part 1, Corrosion of Steel in Concrete, Durability of Reinforced Concrete Structures, BRE Center for Concrete Construction, (2000)

4. L. Bertolini, B. Elsener, P. Pedeferri, R.P. Polder: Corrosion of steel in concrete, WILEY - VCH, Weinheim (2004)

5. BRE Digest 444 Part 3, Corrosion of Steel in Concrete, Protection and Remediation, BRE Center for Concrete Construction, (2000)

6. C. Christodoulou, ... et al.: Long-term performance of surface impregnation of reinforced concrete structures with silane. Construction and Building Materials 48 (2013), pp.708-716

7. L. Zhichao, W. Hansen: Effectiveness of Concrete Surface Treatment Materials in Reducing ChlorideInduced Reinforcement Corrosion, Cement Concrete Comp. 69 (2016): pp. 49-60

8. C. D. Murray, R. Deschenes, W. M. Hale: Durability of silane sealer in highly alkaline environment, ACI Materials Journal 113 (2016) 4, pp. 387-393

9. ACI 515.2R-13, Guide to Selecting Protective Treatments for Concrete, American Concrete Institute (2013)

10. A.M. Vaysburd, P.H. Emmons: Corrosion inhibitors and other protective systems in concrete repair: concepts or mis concepts, Cement\&Concrete Composites, 26 (2004), pp. 255-263

11. V.T. Ngala, C.L. Page, M.M. Page: Corrosion inhibitor systems for remedial treatment of reinforced concrete Part2: sodium monofluorophosphate, Corrosion Science 45 (2003), pp. 1523-1537

12. FHWA-RD-01-097, Long-Term Performance of Corrosion Inhibitors Used in Repair of Reinforced Concrete Bridge Components, Federal Highway Administration Research and Technology (2002)

13. B. Elsener: Corrosion inhibitors for steel in concrete, International Congress on Advanced Materials, (2000)

14. M. Ormellese, M. Berra, F. Bolzoni, T. Pastore: Corrosion inhibitors for chloride induced corrosion in reinforced concrete structures, Cement and concrete Research 36 (2006), pp. 536-547

15. Y. Schiegg, F. Hunkeler, H. Ungricht: The effectiveness of corrosion inhibitors - a field study, $16^{\text {th }}$ Congress of IABSE, (2000)

16. A.I. Karayan, Y. Cubides, H. Castaneda: Evaluation of different surface applied corrosion inhibitors systems on reinforced concrete structures based on electrochemical techniques and standard testing, Department of Defense Allied Nations Conference proceedings, Paper No. 2017-0000

17. X. Pan, Z. Shi, C. Shi, T.C. Ling, N. Li: A review on concrete surface treatment Part I: Types and mechanisms, Construction and Building Materials. 132. 578-590. 10.1016/j.conbuildmat.2016.12.025.

18. ASTM G109-07, Standard Test Method for Determining Effects of Chemical Admixtures on Corrosion of Embedded Steel Reinforcement in Concrete Exposed to Chloride Environments, ASTM International, (2013) 